\title{
Predição da Composição Corporal e dos Requisitos de Energia e Proteína para Ganho de Peso de Bovinos, Não-Castrados, Alimentados com Rações Contendo Diferentes Níveis de Concentrado ${ }^{1}$
}

\begin{abstract}
Antonia Sherlânea Chaves Véras ${ }^{2}$, Sebastião de Campos Valadares Filho ${ }^{3}$, José Fernando Coelho da Silva ${ }^{4}$, Mário Fonseca Paulino ${ }^{3}$, Paulo Roberto Cecon ${ }^{5}$, Marcelo de Andrade Ferreira ${ }^{2}$, Maria Ignez Leão ${ }^{3}$, Rilene Ferreira Diniz Valadares ${ }^{6}$, Eduardo Henrique Bevitori Kling de Moraes ${ }^{7}$
\end{abstract}

RESUMO - Este trabalho foi conduzido com o objetivo de compilar dados de dois experimentos (I e II) relativos aos requisitos energéticos e protéicos, para ampliar as informações disponíveis sobre exigências nutricionais de bovinos em nível nacional. No experimento I, foram utilizados 30 bovinos Nelore não-castrados e no experimento II, 29 bovinos F1 Simental $x$ Nelore, não-castrados. Nos dois experimentos, os animais foram alimentados com dietas contendo 25; 37,5; 50; 62,5; e 75\% de concentrado. As metodologias e os procedimentos foram padronizados e possibilitaram análise conjunta dos dados. Foram ajustadas equações de regressão do logaritmo do conteúdo de gordura, proteína e energia em função do logaritmo do peso de corpo vazio (PCVZ) dos animais. Derivando-se estas equações, foi obtida a composição do ganho de PCVZ. Os resultados indicaram que, para conversão do ganho de peso vivo em ganho de peso vazio, deve-se multiplicar o ganho de peso vivo pelo fator 0,964. Os requerimentos líquidos de proteína e energia de um bovino com $400 \mathrm{~kg}$ de PV foram de $140,26 \mathrm{~g} / \mathrm{kg}$ de ganho de peso de corpo vazio (GPCVZ) e 3,19 Mcal/kg GPCVZ, respectivamente. Os requisitos de PMm, PMg e PB foram de 339,88 e 285,08 g/kg GPCVZe 939,54 g/dia, respectivamente. As exigências de EMe NDT, para ganho de peso, foram de 8,62 Mcal $/ \mathrm{kg} \mathrm{GPCVZe} \mathrm{2,38} \mathrm{kg/kg} \mathrm{GPCVZ,}$ respectivamente, para dietas com teor de EM de 2,4 Mcal/kg de MS. Para dietas com concentração de EM de 2,6 Mcal/kg de MS, os requisitos foram de 6,38 Mcal/kg GPCVZ e 1,76 kg/kg GPCVZ, respectivamente.

Palavras-chave: energia, exigências, F1 Simental x Nelore, Nelore, proteína

\section{Prediction of Body Composition and of Energy and Protein Requirements for Weight Gain of Nellore Bulls, Fed Diet with Different Levels of Concentrate}

\begin{abstract}
This work was carried out to compile data of two experiments (I and II) of energy and protein requirements, to enlarge the available information on nutritional requirements of bovine in national level. In the experiment I, $30 \mathrm{Nellore}$ bulls were used and in the experiment II, 29 F1 Simental x Nellore bulls were used. In the both experiments, the animals were fed diets with $25,37.5,50,62.5$, and $75 \%$ of concentrate. The methodologies and the procedures were standardized and facilitated the overall analysis of the data. Regression equations of fat, protein and energy contents were fitted on the empty body weight (EBW) of animals. By deriving these equations, the composition of EBW gain was obtained. The results showed that, for live weight gain: empty body weight gain ratio, the live weight gain should be multiplied by the factor .964. The protein and energy net requirements of a $400 \mathrm{~kg} \mathrm{LW}$ bovine were $140.26 \mathrm{~g} / \mathrm{kg}$ empty body weight gain (EBWG) and 3.19 Mcal/kg EBWG, respectively. The MPm, MPg and CP requirements were 339.88 and $285.08 \mathrm{~g} / \mathrm{kg} \mathrm{GPCVZ} \mathrm{e} \mathrm{939,54} \mathrm{g/day,} \mathrm{respectively.} \mathrm{The} \mathrm{ME}$ and TDN requirements, for weight gain, were $8.62 \mathrm{Mcal} / \mathrm{kg}$ EBWG and $2.38 \mathrm{~kg} / \mathrm{kg}$ EBWG, respectively, for diets with ME content of $2.4 \mathrm{Mcal} / \mathrm{kg}$ DM. For diets with ME content of $2.6 \mathrm{Mcal} / \mathrm{kg} \mathrm{DM}$, the requirements were of $6.38 \mathrm{Mcal} / \mathrm{kg}$ EBWG and $1.76 \mathrm{~kg} / \mathrm{kg}$ EBWG, respectively.
\end{abstract}

Key Words: energy, requirements, F1 Simental x Nellore, Nellore, protein

\footnotetext{
${ }^{1}$ Parte da tese de Doutorado do primeiro autor, parcialmente financiada pela FINEP

2 Professor do DZ/UFRPE. E.mail: sherlanea@uol.com.br

3 Professor do DZ/UFV.

4 Professor do LZNA-CCTA/UENF.

5 Professor do DINF/UFV.

6 Professor do DMV/UFV.

7 Estudante de Graduação em Zootecnia/UFV.
} 


\section{Introdução}

A avaliação da composição corporal é necessária em estudos de nutrição animal, tanto para predição da performance, quanto para determinação dos requerimentos nutricionais dos animais. Os componentes químico-físicos do corpo variam, durante o crescimento, de forma paralela. Fatores como idade, peso, espécie, raça, condição sexual e nível de ingestão de energia influenciam estas variações e conduzem a diferenças nos requisitos nutricionais dos animais.

O AGRICULTURAL AND FOOD RESEARCH COUNCIL - AFRC (1993), considerando que o estádio de maturidade fisiológica é importante nos estudos de composição química corporal, propôs que os requisitos nutricionais dos animais sejam corrigidos pelo fator maturidade fisiológica, já que, à medida que a maturidade avança, ocorre aumento na proporção de gordura e concomitante decréscimo nas concentrações de água, proteína e minerais no corpo animal.

Se comparados animais de maturidade fisiológica precoce em relação aos de maturidade tardia, observam-se maiores conteúdos corporais de gordura e menores de proteína nos primeiros. Este fato se deve ao menor potencial dos animais precoces em depositar proteína, aliado à maior propensão em depositar gordura.

O AGRICULTURAL RESEARCH COUNCIL - ARC (1980), para animais castrados de porte médio, demonstrou quedas sucessivas no conteúdo de proteína por $\mathrm{kg}$ de PCVZ e por kg de ganho de PCVZ. FONTES (1995), em compilação de dados de vários experimentos conduzidos no Brasil com zebuínos e mestiços Europeu-zebu, observou que as concentrações de proteína diminuíram e as de gordura e energia aumentaram, com a elevação do peso corporal dos animais. Resultados semelhantes foram verificados por PAULINO et al. (1997), FERREIRA et al. (1998a,b) e VÉRAS et al. (2000b), entre outros. Segundo GRANT e HELFERICH (1991), isto se deve à desaceleração do crescimento muscular, à medida que o peso do animal se eleva.

As principais diferenças em relação à condição sexual dos animais são observadas quanto ao tecido adiposo. Considerando-se animais pertencentes à mesma raça e com peso de corpo vazio (PCVZ) similar, fêmeas possuem maior quantidade corporal de gordura que machos castrados, e estes, mais que os inteiros. Este comportamento se reflete nas concentrações de energia corporal e nas respectivas exigências energéticas para ganho.
A densidade energética da ração pode direcionar o uso da energia para síntese de proteína ou de gordura, modificando a composição do crescimento (ROBELIN e GEAY, 1984). JONES et al. (1985) observaram que animais alimentados com dietas à base de concentrado, apresentaram maiores teores de gordura na carcaça que aqueles cujas dietas eram à base de volumoso. Contudo, a extensão na qual a composição do corpo é modificada pelo nível nutricional, também é afetada pela taxa de ganho de peso vazio e pela maturidade do animal.

Vários autores (Byers, 1980 e Garrett, 1979, citados por FERRELL e JENKINS, 1998a,b; BYERS e ROMPALA, 1980; OWENS et al., 1995), relataram que as taxas de acréscimo de proteína e de energia são maximizadas a uma determinada taxa de ganho de PCVZ, a partir da qual se mantêm constantes. Este comportamento foi verificado por FERREIRA et al. (1998b) e por VÉRAS et al. (2000b), com animais F1 Simental x Nelore e Nelore, respectivamente, alimentados com dietas com níveis crescentes de concentrado.

Animais tardios são considerados ideais em sistemas de nível nutricional elevado, porque estes animais podem ser abatidos com pesos maiores, alcançando o máximo desenvolvimento muscular, sem, contudo, depositar gordura em excesso. Já animais precoces apresentam maiores acúmulos de gordura e menores de proteína, mas o abate mais cedo destes animais pode oferecer um produto de melhor qualidade no mercado (BERG e BUTTERFIELD,1976).

As diferenças nas exigências de energia e proteína para ganho de peso se devem às diferenças na composição do ganho, já que os requisitos líquidos de energia para crescimento consistem na quantidade de energia depositada nos tecidos, que é função das proporções de gordura e proteína no ganho do corpo vazio, e as exigências líquidas de proteína são função do conteúdo de matéria seca livre de gordura do peso ganho (NATIONAL RESEARCH COUNCIL - NRC, 1996).

Segundo GEAY (1984), os requisitos protéicos para ganho de peso variam com a raça, o sexo e a taxa de ganho de peso, sendo maiores em animais nãocastrados, em relação a castrados e, para a mesma condição sexual, são maiores para animais de maturidade tardia, do que para aqueles de maturidade precoce. FONTES (1995) em análise conjunta de vários experimentos, analisou os dados relativos a animais castrados separadamente dos animais nãocastrados, e concluiu que os primeiros eram menos 
exigentes em proteína e mais exigentes em energia para ganho de peso que os inteiros.

Os requerimentos dietéticos de energia e de proteína são obtidos a partir da correção dos requisitos líquidos por um fator de eficiência de utilização.

O NRC (1984) apresentou valores de eficiência de utilização da energia metabolizável (EUEM) para ganho de peso de 29 a $47,3 \%$, para rações com diferentes proporções volumoso:concentrado, cujos teores de EM variaram de 2,0 a 3,2 Mcal $/ \mathrm{kg}$ de matéria seca, obtidos a partir de equações de regressão entre a ELm ou ELg e a concentração de EM da dieta. O ARC (1980) desenvolveu equações lineares para o cálculo da eficiência de utilização da EM para crescimento a partir da metabolizabilidade da energia bruta da dieta. O AFRC (1993) preconizou eficiência de utilização da proteína metabolizável (PM) para ganho de peso como 59\%, enquanto o NRC (1996) considera que a eficiência de utilização da PM varia de acordo com o PV.

$\mathrm{O}$ conhecimento dos requerimentos de proteína bruta (PB) é importante para a formulação de rações. Segundo o NRC (1996), as exigências de PM consistem na soma da proteína não-degradada no rúmen digestível $\left(\mathrm{PNDR}_{\mathrm{D}}\right)$ e a proteína microbiana verdadeira digestível $\left(\mathrm{PMIV}_{\mathrm{D}}\right)$, e os requerimentos de proteína bruta $(\mathrm{PB})$ são obtidos pelo somatório da proteína degradada no rúmen (PDR) e a proteína não-degradada no rúmen (PNDR). Para este sistema, a PDR consiste em $130 \mathrm{~g}$ de $\mathrm{PB} / \mathrm{kg}$ de nutrientes digestíveis totais (NDT) consumidos. Conhecendose a síntese de proteína microbiana e assumindo-se que $80 \%$ desta é verdadeira e possui digestibilidade de $80 \%$, chega-se à PMIV $_{\mathrm{D}}$. A PNDR $_{\mathrm{D}}$ é obtida pela PNDR com correção de $80 \%$ de digestibilidade.

Desde 1980, vários trabalhos têm sido conduzidos na Universidade Federal de Viçosa objetivando determinar a composiçãocorporal e predizer as exigências nutricionais de bovídeos. Uma linha de pesquisa mais recente trata da determinação destes parâmetros em estudos conduzidos individualmente, com animais de alguns grupos genéticos, alimentados com dietas semelhantes.

FERREIRA et al. (1998a,b) e VÉRAS et al. (2000b), determinaram a composição química corporal e as exigências energéticas e protéicas para ganho de peso de bovinos F1 Simental x Nelore e Nelore, respectivamente, todos não-castrados. $\mathrm{O}$ presente trabalho foi conduzido objetivando compilar os dados dos referidos estudos, para a predição da composição corporal e dos requerimentos energéticos e protéicos de bovinos alimentados com dietas com $25 ; 37,5 ; 50$; 62,5 ; e $75 \%$ de concentrado.

\section{Material e Métodos}

Maiores detalhes sobre o local e as condições experimentais, as dietas, o sistema de alimentação, o manejo e os animais utilizados, os procedimentos de abate, as coletas e as análises químicas dos alimentos e dos tecidos, o delineamento experimental e as análises estatísticas são descritos por FERREIRA et al. (1998a,b) e por VÉRAS et al. (2000a,b).

As metodologias e os procedimentos nos dois experimentos foram padronizados e possibilitaram análise conjunta dos dados. Assim, os experimentos tiveram em comum:

1) Período de adaptação à dieta e às instalações: mínimo de 40 dias;

2) medidas sanitárias: controle contra endo e ecto-parasitas;

3) suplementação vitamínica: vitamina A injetável;

4) níveis de concentrado nas dietas: $25 ; 37,5 ; 50$; 62,5 ; e $75 \%$;

5) volumoso: fenos de braquiária e coast-cross, na proporção de $50 \%$, cada;

6) instalações: baias individuais;

7) consumo de alimentos: registros diários dos alimentos fornecidos e coletas semanais das sobras;

8) análise bromatológica dos fenos, dos concentrados e das sobras: segundo descrito por SILVA (1990);

9) pesagens intermediárias dos animais: a cada 28 dias;

10) peso de abate: $100 \%$ do peso à maturidade das fêmeas de seu grupo racial, ou seja, $500 \mathrm{~kg}$ para os animais F1 Simental x Nelore e $450 \mathrm{~kg}$ para os Nelore;

11) amostragem da carcaça e proporção de tecidos na carcaça: seção entre a $9^{\mathrm{a}}$ e $11^{\mathrm{a}}$ costelas e equações preconizadas por HANKINS e HOWE (1946);

12) determinação do peso do corpo vazio (PCVZ): soma dos pesos da carcaça, do sangue, da cabeça, do couro, da cauda, dos membros, das vísceras e dos órgãos;

13) composição química corporal: análises químicas das partes do corpo animal, segundo SILVA (1990);

14) procedimento anterior às análises químicas: lavagens sucessivas das amostras, exceto as de sangue, com éter de petróleo (prédesengorduramento);

15) metodologia para estimativa da energia retida: 
abate comparativo;

16) estimativa da composição corporal: equações de regressão do logaritmo do conteúdo corporal de proteína, gordura e energia, em função do logaritmo do PCVZ, segundo o ARC (1980). Para cada tratamento, as equações foram construídas adicionado-se os valores relativos aos dos animais referência;

17) predição dos conteúdos de gordura, proteína e energia por kg de ganho de PCVZ: derivadas das equações constantes no item 16 ;

18) determinação dos requisitos líquidos de proteína e energia para ganho de um kg de PCVZ: conteúdos de proteína e energia no ganho de corpo vazio, obtidos por meio das equações constantes no item 17.

Para a análise conjunta dos dados, VÉRAS et al. (2000b) aplicaram o teste de identidade de modelos, proposto por REGAZZI (1996), nas equações de regressão do logaritmo dos conteúdos de gordura, proteína ou energia no corpo vazio, em função do logaritmo do peso do corpo vazio, para todos os tratamentos. Os resultados indicaram que os tratamentos não diferiram entre si. Procedimento semelhante foi efetuado com os dados relativos ao experimento conduzido por FERREIRA et al. (1998a), cujos resultados também demonstraram não haver diferença para os tratamentos.

As comparações entre as equações de regressão dos parâmetros avaliados para cada tratamento (25; 37,5; 50; 62,5; e 75\% de concentrado) foram realizadas segundo metodologia proposta por REGAZZI (1996), para testar identidade de modelos dos dados agrupados: 29 observações (FERREIRA et al., 1998a) e 30 observações (VÉRAS et al., 2000b), adicionando-se os dados relativos aos dos animais dos grupos referência dos dois experimentos.

A determinação da energia corporal foi obtida a partir dos teores corporais de proteína e gordura e seus respectivos equivalentes calóricos, conforme a equação preconizada pelo ARC (1980):

$$
\mathrm{CE}=5,6405 \mathrm{X}+9,3929 \mathrm{Y} \text {, }
$$

em que: $\mathrm{CE}=$ conteúdo energético (Mcal); $\mathrm{X}=$ proteína corporal $(\mathrm{kg}) ; \mathrm{Y}=\operatorname{gordura}$ corporal $(\mathrm{kg})$.

Os conteúdos de gordura, proteína e energia retidos no corpo dos animais de cada tratamento, e para todos os tratamentos em conjunto, foram estimados por meio de equações de regressão do logaritmo do conteúdo corporal de proteína, gordura e energia, em função do logaritmo do PCVZ, segundo o ARC (1980), conforme o seguinte modelo:

$$
\mathrm{Y}=\mathrm{a}+\mathrm{bX}+\mathrm{e}
$$

em que: $\mathrm{Y}=$ logaritmo do conteúdo total de proteína $(\mathrm{kg})$, gordura $(\mathrm{kg})$ e energia (Mcal) retido no corpo vazio; $a=$ efeito da média (intercepta); $b=$ coeficiente de regressão do logaritmo do conteúdo de gordura, proteína ou energia, em função do logaritmo do PCVZ; X = logaritmo do PCVZ; e = erro aleatório.

Derivando-se as equações de predição do conteúdo corporal de gordura, proteína ou energia em função do logaritmo do PCVZ foram obtidas as equações de predição dos conteúdos de gordura, proteína e energia por kg de ganho de PCVZ. As exigências líquidas de proteína e de energia para ganho de um kg de PCVZ corresponderam aos respectivos conteúdos no ganho de corpo vazio e foram obtidas, juntamente com o conteúdo de gordura no ganho de corpo vazio, a partir de equação do tipo:

$$
\mathrm{Y}^{\prime}=\mathrm{b} \cdot 10^{\mathrm{a}} \cdot \mathrm{X}^{\mathrm{b}-1}
$$

em que: $\mathrm{Y}^{\prime}=$ conteúdo de gordura no ganho, ou exigência líquida de proteína, ou de energia; a e $b=$ intercepta e coeficiente de regressão, respectivamente, das equações de predição dos conteúdos corporais de gordura, proteína ou energia; $X=$ PCVZ $(\mathrm{kg})$.

Para a conversão do PV em PCVZ, dentro do intervalo de pesos incluídos nos trabalhos, utilizouse a equação obtida pela regressão do PCVZ dos 59 animais mantidos nos experimentos, em função dos respectivos PV. Para conversão das exigências para ganho de PCVZ em exigências para ganho de $\mathrm{PV}$, utilizou-se o fator obtido a partir dos dados experimentais.

Foi efetuada equação de regressão entre a energia retida (ER) e o ganho diário de PCVZ (GDPCVZ) para um dado PCVZ, conforme preconizado pelos NRC's (1984, 1996).

Os requisitos dietéticos de energia foram obtidos a partir da relação entre a ELg obtida para os dados agrupados dos dois ensaios e a eficiência de utilização da EM para ganho de peso, determinada em análise conjunta dos dados por VÉRAS et al. (2001), pela equação: $\mathrm{ELg}=43,099 \mathrm{EM}^{3}-316,65$ $\mathrm{EM}^{2}+776,79 \mathrm{EM}-635,31, \mathrm{R}^{2}=0,99 . \quad$ As exigências de NDT foram calculadas dividindo-se as exigências de EM por 0,82, obtendo-se as exigências de energia digestível (ED) e, posteriormente, dividindo-se as exigências de ED por 4,409 (COELHO DA SILVA e LEÃO, 1979). Os requisitos de PM e proteína bruta (PB) foram determinados segundo o NRC (1996). 


\section{Resultados e Discussão}

A equação geral obtida para predição do PCVZ a partir do peso vivo (PV) ajustada para os dados dos dois experimentos foi: $\mathrm{PCVZ}=-39,249+0,964 \mathrm{PV}$; $\mathrm{r}^{2}=0,92$. Para um animal pesando $400 \mathrm{~kg}$ de PV, o PCVZ estimado a partir desta equação foi de 346,35 kg, superior ao obtido por FERREIRA et al. (1998a,b), para animais F1 Simental x Nelore, de $338,3 \mathrm{~kg}$, e próximo ao relatado por VÉRAS et al. (2000b), para animais Nelore, de $350,18 \mathrm{~kg}$.

A partir da equação anterior, foi obtida a equação para a estimativa do PV em função do PCVZ, objetivando possibilitar a conversão das exigências para ganho de PCVZ em exigências para ganho de PV. A equação obtida foi: $\mathrm{PV}=$ 1,037 (PCVZ + 46,262). Portanto, nas condições do presente experimento, o ganho de um $\mathrm{kg}$ de PCVZ corresponde ao ganho de 1,04 kg de PV. Para obtenção dos requisitos líquidos para ganho de $\mathrm{PV}$, os requerimentos para ganho de um $\mathrm{kg}$ de PCVZ devem ser divididos pelo fator 1,04 , ou seja, o ganho de um $\mathrm{kg}$ de PV corresponde ao ganho de 0,964 de PCVZ.

Na Tabela 1 são apresentados os parâmetros das equações de regressão do logaritmo dos conteúdos de gordura $(\mathrm{kg})$, proteína $(\mathrm{kg})$ e energia (Mcal) no corpo vazio, em função do logaritmo do PCVZ, obtidos para os dados agrupados dos dois experimentos, para cada tratamento $(25 ; 37,5 ; 50 ; 62,5$ e $75 \%)$ e para todos tratamentos em conjunto. Pode-se observar que os coeficientes de regressão $\left(\mathrm{r}^{2}\right)$ demonstram que as equações de predição dos conteúdos corporais de gordura e de energia não se ajustaram bem aos dados, o que não ocorreu em relação ao conteúdo de proteína corporal.

$\mathrm{O}$ teste de identidade de modelos aplicado às equações de regressão do logaritmo do conteúdo corporal de gordura, proteína e energia, em função do logaritmo do PCVZ, para os tratamentos, demonstrou não haver diferença para os níveis de inclusão de concentrado. Portanto, pode-se recomendar o uso da equação conjunta.

As concentrações de gordura e proteína, em $\mathrm{g} / \mathrm{kg}$ de PCVZ, e de energia, em Mcal $/ \mathrm{kg}$ de PCVZ, são apresentadas na Tabela 2. Os conteúdos de gordura, proteína e energia por kg de ganho de PCVZ são apresentados na Tabela 3, sendo que os conteúdos de proteína e energia para ganho de PCVZ correspondem aos respectivos requisitos líquidos para ganho de $1 \mathrm{~kg}$ de $\mathrm{PCVZ}$.

$\mathrm{Na}$ Tabela 2 verifica-se que as concentrações de gordura e energia aumentaram, enquanto a de proteína,
Tabela 1 - Parâmetros das equações de regressão do logaritmo dos conteúdos de gordura $(\mathrm{kg})$, proteína (kg) e energia (Mcal) no corpo vazio, em função do logaritmo do peso do corpo vazio $(\mathrm{kg})$, de bovinos, para os diferentes níveis de concentrado (NC) na ração e em conjunto (CONJ)

Table 1 - Parameters of the regression equations of logarithm of fat $(\mathrm{kg})$ protein $(\mathrm{kg})$ and energy (Mcal) contents in the empty body, in function of the logarithm of empty body weight $(\mathrm{kg})$ of bulls, for the different concentrate levels in the diet and in overall

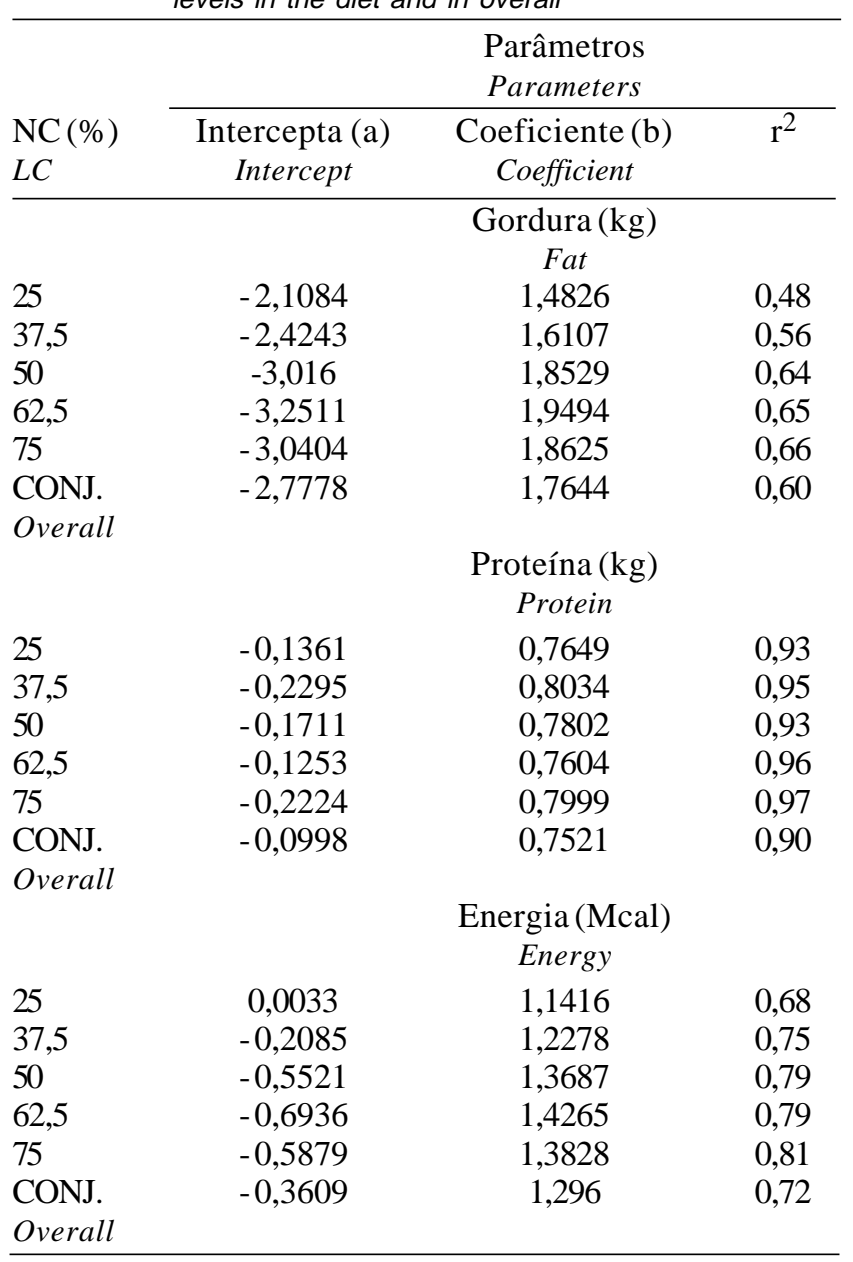

em g/kg de PCVZ, diminuiu, com o aumento do PV. FERREIRA et al. (1998a), trabalhando com bovinos F1 Simental X Nelore não-castrados, VÉRAS et al. (2000b), com animais Nelore, não-castrados, e FONTES (1995), em compilação de vários experimentos, entre outros, observaram aumento nas concentrações de gordura e energia e diminuição na concentração de proteína com a elevação do PV. Segundo GRANT e HELFERICH (1991), estas alterações são devido à desaceleração do crescimento muscular, que pode ser constatada pelo menor ganho de proteína por kg de ganho de PCVZ (Tabela 3) e concomitante aumento na deposição de gordura (Tabela 2) e do ganho de gordura por $\mathrm{kg}$ de PCVZ (Tabela 3), à medida que o peso corporal aumen- 
1132

VÉRAS et al.

Tabela 2 - Estimativa dos conteúdos de gordura e proteína (g/kg PCVZ) e de energia no peso do corpo vazio (Mcal/kg PCVZ), de bovinos, para os diferentes níveis de concentrado na dieta e em conjunto (CONJ.), em função do peso vivo (PV) ou do PCVZ

Table 2 - Estimate of fat and protein ( $\mathrm{g} / \mathrm{kg}$ EBW) and energy contents in the empty body weight gain (Mcal/kg EBW), of bulls, for the different concentrate levels in the diet and in overall, in function of the live weight (LW) or the EBW

\begin{tabular}{lcc}
\hline $\mathrm{PV}(\mathrm{kg})$ & $\mathrm{PCVZ}(\mathrm{kg})$ & Níveis de concentrado $(\%)$ \\
$L W$ & $E B W$ & Levels of concentrate
\end{tabular}

\begin{tabular}{|c|c|c|c|c|c|c|c|}
\hline & & 25 & 37,5 & 50 & 62,5 & 75 & CONJ. \\
\hline & & \multicolumn{6}{|c|}{$\begin{array}{c}\text { Gordura (g/kg PCVZ) } \\
\text { Fat }(g / k g E B W)\end{array}$} \\
\hline 300 & 249,95 & 111,89 & 109,67 & 106,94 & 106,03 & 106,60 & 113,53 \\
\hline 350 & 298,15 & 121,83 & 122,13 & 124,29 & 125,35 & 124,11 & 129,91 \\
\hline 400 & 346,35 & 130,97 & 133,84 & 141,24 & 144,52 & 141,23 & 145,68 \\
\hline 450 & 394,55 & 139,47 & 144,92 & 157,84 & 163,55 & 158,03 & 160,94 \\
\hline \multirow[t]{2}{*}{500} & 442,75 & 147,45 & 155,49 & 174,14 & 182,46 & 174,55 & 175,76 \\
\hline & & \multicolumn{6}{|c|}{$\begin{array}{l}\text { Proteína (g/kg PCVZ) } \\
\text { Protein ( }(g / k g \text { EBW) }\end{array}$} \\
\hline 300 & 249,95 & 199,60 & 199,11 & 200,38 & 199,61 & 198,51 & 202,20 \\
\hline 350 & 298,15 & 191,50 & 192,32 & 192,76 & 191,35 & 191,63 & 193,55 \\
\hline 400 & 346,35 & 184,87 & 186,74 & 186,52 & 184,60 & 185,97 & 186,49 \\
\hline 450 & 394,55 & 179,29 & 182,01 & 181,25 & 178,93 & 181,18 & 180,56 \\
\hline \multirow[t]{2}{*}{500} & 442,75 & 174,50 & 177,94 & 176,72 & 174,05 & 177,05 & 175,48 \\
\hline & & \multicolumn{6}{|c|}{$\begin{array}{c}\text { Energia (Mcal/kg PCVZ) } \\
\text { Energy }(\text { Mcal/kg EBW) }\end{array}$} \\
\hline 300 & 249,95 & 2,20 & 2,18 & 2,15 & 2,13 & 2,14 & 2,23 \\
\hline 350 & 298,15 & 2,26 & 2,27 & 2,29 & 2,30 & 2,29 & 2,35 \\
\hline 400 & 346,35 & 2,31 & 2,34 & 2,42 & 2,45 & 2,42 & 2,46 \\
\hline 450 & 394,55 & 2,35 & 2,41 & 2,54 & 2,59 & 2,55 & 2,56 \\
\hline 500 & 442,75 & 2,39 & 2,48 & 2,65 & 2,72 & 2,66 & 2,64 \\
\hline
\end{tabular}

tou, o que pode ser evidenciado pelo aumento na concentração de gordura e redução na de proteína.

As estimativas dos requerimentos de EM para ganho de peso, em Mcal por kg de ganho de peso do corpo vazio (Mcal $/ \mathrm{kg} \mathrm{GPCVZ),} \mathrm{e} \mathrm{de} \mathrm{NDT,} \mathrm{em} \mathrm{kg/kg}$ de GPCVZ, para as concentrações de EM de 2,4 e 2,6 Mcal/kg de MS, são apresentadas na Tabela 4, e foram obtidas utilizando-se a relação entre os requi- sitos líquidos estimados para os dados em conjunto e a eficiência de utilização da energia metabolizável (EUEM) para ganho de peso, determinada para os dados agrupados dos dois experimentos por VÉRAS et al. (2001). Apenas foram utilizados os valores relativos às exigências líquidas de energia dos dados em conjunto, porque o teste de identidade de modelos indicou não haver diferença entre os tratamentos.

Tabela 3 - Exigências líquidas de proteína (g) e energia (Mcal), por kg de ganho de peso do corpo vazio (GPCVZ), e conteúdo de gordura no ganho de peso do corpo vazio ( $/ \mathrm{kg}$ GPCVZ) de bovinos, para os níveis de concentrado na dieta, em função do peso vivo (PV) ou do PCVZ

Table 3 - Net requirements of protein (g) and energy (Mcal), by kg empty body weight gain (EBWG), and fat content in the ( $g / k g$ EBWG), of bulls, for the concentrate levels in the diet, in function of the live weight (LW) or the EBW

\begin{tabular}{|c|c|c|c|c|}
\hline \multirow[b]{2}{*}{$\begin{array}{l}\mathrm{PV}(\mathrm{kg}) \\
L W\end{array}$} & \multirow[b]{2}{*}{$\begin{array}{l}\mathrm{PCVZ}(\mathrm{kg}) \\
\quad E B W\end{array}$} & \multicolumn{2}{|c|}{$\begin{array}{c}\text { Exigências } \\
\text { Requirements } \\
\end{array}$} & \multirow[b]{2}{*}{$\begin{array}{c}\text { Conteúdos de gordura } \\
\text { (g/kg GPCVZ) } \\
\text { Fat contents }(\mathrm{g} / \mathrm{kg} \text { EBWG) }\end{array}$} \\
\hline & & $\begin{array}{l}\text { Proteína (g/kg GPCVZ) } \\
\text { Protein }(g / k g E B W G)\end{array}$ & $\begin{array}{l}\text { Energia (Mcal/kg GPCVZ) } \\
\text { Energy }(\text { Mcal/kg EBWG) }\end{array}$ & \\
\hline 300 & 249,95 & 152,07 & 2,89 & 200,32 \\
\hline 350 & 298,15 & 145,57 & 3,05 & 229,22 \\
\hline 400 & 346,35 & 140,26 & 3,19 & 257,04 \\
\hline 450 & 394,55 & 135,80 & 3,31 & 283,96 \\
\hline 500 & 442,75 & 131,98 & 3,43 & 310,11 \\
\hline
\end{tabular}


Rev. bras. zootec.

Tabela 4 - Estimativa dos requisitos de energia metabolizável (EM), por kg de ganho de peso de corpo vazio (Mcal/ $\mathrm{kg}$ GPCVZ) e de nutrientes digestíveis totais (NDT), em kg/kg GPCVZ, em função das concentrações de EM da dieta (Mcal/kg de MS), e respectivas eficiências de utilização da energia metabolizável para ganho de peso (kf), em \%, para diferentes pesos vivo (PV) e de corpo vazio (PCVZ) de bovinos

Table 4 - Estimate of the metabolizable energy (ME) requirements, by $\mathrm{kg}$ empty body weight gain (Mcal/kg EBWG) and total digestible nutrients (TDN), in $\mathrm{kg} / \mathrm{kg}$ EBWG, in function of the dietary ME concentrations (Mcal DM) and respective efficiency of utilization of metabolizable energy for weight gain ( $\mathrm{kf})$, in \%, of different live weight (LW) and empty body weight (EBW) of bulls

\begin{tabular}{|c|c|c|c|c|c|}
\hline \multirow[b]{2}{*}{$\begin{array}{c}\mathrm{PV}(\mathrm{kg}) \\
L W\end{array}$} & \multirow[b]{2}{*}{$\begin{array}{c}P C V Z(\mathrm{~kg}) \\
E B W \\
\end{array}$} & \multicolumn{4}{|c|}{$\begin{array}{l}\text { EM da dieta } \\
\text { Dietary } M E\end{array}$} \\
\hline & & 2,4 & $(\mathrm{kf}=0,37)$ & 2,6 & $(\mathrm{kf}=0,50)$ \\
\hline & & \multicolumn{4}{|c|}{$\begin{array}{l}\text { Exigências } \\
\text { Requirements }\end{array}$} \\
\hline & & $\mathrm{EM}$ & NDT & EM & NDT \\
\hline 300 & 249,95 & 7,81 & 2,11 & 5,78 & 1,60 \\
\hline 350 & 298,15 & 8,24 & 2,28 & 6,10 & 1,69 \\
\hline 400 & 346,35 & 8,62 & 2,38 & 6,38 & 1,76 \\
\hline 450 & 394,55 & 8,95 & 2,47 & 6,62 & 1,83 \\
\hline 500 & 442,75 & 9,27 & 2,56 & 6,86 & 1,90 \\
\hline
\end{tabular}

As exigências de proteína metabolizável para mantença $(\mathrm{PMm})$ e ganho de peso $(\mathrm{PMg})$, são apresentadas na Tabela 5, onde pode-se observar que os requisitos de PM para mantença aumentaram com a elevação do PV. Já os requerimentos de $\mathrm{PMg}$ apresentaram o mesmo comportamento verificado para os respectivos requisitos líquidos e, de um modo geral, foram próximos aos preconizados pelo NRC (1996) para bovinos com 300, 350, 400 e $450 \mathrm{~kg}$, que são de 303, 298, 272 e 246 g/dia, respectivamente.

A partir dos requisitos de PM apresentados na Tabela 5 e, utilizando-se a metodologia recomendada pelo NRC (1996), para conversão dos requerimentos totais de PM em exigências de proteína bruta (PB), as exigências de proteína degradada no rúmen, a proteína não-degradada no rúmen e os requisitos diários

Tabela 5 - Exigências de proteína metabolizável para mantença (PMm) e ganho (PMg) de $1 \mathrm{~kg}$ de PCVZ ( $\mathrm{g} / \mathrm{kg}$ GPCVZ) de bovinos, em função do peso vivo (PV) ou do PCVZ

Table 5 - Requirements of metabolizable protein for maintenance $(\mathrm{MPm})$ and gain $(\mathrm{MPg})$ of $1 \mathrm{~kg}$ EBW $(\mathrm{g} / \mathrm{kg}$ EBWG) of bulls, in function of the live weight (LW) or EBW

\begin{tabular}{cccc}
\hline $\mathrm{PV}(\mathrm{kg})$ & $\begin{array}{c}\mathrm{PCVZ}(\mathrm{kg}) \\
L W\end{array}$ & $\begin{array}{c}\mathrm{PMm}^{1} \\
M B W\end{array}$ & $\begin{array}{c}\mathrm{PMg}^{2} \\
\mathrm{MPg}\end{array}$ \\
\hline 300 & 249,95 & 273,92 & 309,09 \\
350 & 298,15 & 307,49 & 295,87 \\
400 & 346,35 & 339,88 & 285,08 \\
450 & 394,55 & 371,27 & 276,02 \\
500 & 442,75 & 401,80 & 268,25 \\
\hline
\end{tabular}

$13,8 / \mathrm{kg}^{0,75}$

2 Exigências líquidas/0,492 (Net requirements/492). totais de PB foram calculados, utilizando-se o consumo médio de nutrientes digestíveis totais (NDT) obtido por VÉRAS et al. (2000a) e por FERREIRA et al. (1997), de 6,09 kg/dia, e são apresentados na Tabela 6 .

A equação de regressão efetuada para descrever a relação entre a energia retida (ER) e o ganho diário de PCVZ (GDPCVZ) a dado PCVZ, foi:

$\mathrm{ER}=0,044 * \mathrm{PCVZ}^{0,75} * \mathrm{GDPCVZ}^{1,1578}\left(\mathrm{r}^{2}=0,86\right), \mathrm{em}$ que: $\mathrm{ER}=$ retenção diária de energia , expressa em Mcal.

Esta equação difere da preconizada pelos NRC (1984, 1996), para um novilho de porte médio, que é igual a: $\mathrm{ER}=0,0635 * \mathrm{PCVZ}^{0,75} * \mathrm{GDPCVZ}^{1,097}$. A ER de um animal com ganho médio diário de PCVZ de $1 \mathrm{~kg}$ e com PCVZigual a $400 \mathrm{~kg}$ seria de $3,94 \mathrm{Mcal} / \mathrm{dia}$, utilizando-se a equação obtida no presente trabalho; de 3,76 Mcal/dia, com a equação obtida por FERREIRA (1997); de 4,02, segundo a equação obtida por VÉRAS et al. (2000b); e de 5,68 Mcal/dia a partir da equação preconizada pelos NRC $(1984,1996)$.

As diferenças observadas entre os valores obtidos pela equação utilizada pelos NRC $(1984,1996)$ e os obtidos no presente trabalho são cerca de $44 \%$ e podem, em parte, ser explicadas pelo fator condição sexual; já que, segundo o NRC (1996), animais nãocastrados têm requerimentos energéticos líquidos para ganho de peso, $18 \%$ inferiores aos de novilhos, a um mesmo peso. Também, zebuínos por apresentarem marmoreio na forma de traços, possuiriam apenas cerca de $25 \%$ de gordura corporal, e seus mestiços, com ligeiro marmoreio, próximo a $26 \%$ de gordura, diferente dos $28 \%$ de gordura corporal atribuídos para o novilho de porte médio, considerado como referência pelo NRC (1996). 
1134

Tabela 6 - Exigências de proteína degradada no rúmen (PDR), proteína não-degradada no rúmen (PNDR) e proteína bruta (PB), em g/dia, de bovinos, em função do peso vivo (PV)

Table 6 - Requirements of degraded protein in the rumen (DPR), non degraded protein in the rumen (NDPR) and crude protein $(C P)$, in $g /$ day, of bulls, in function of the live weight (LW)

\begin{tabular}{cccc}
\hline PV $(\mathrm{kg})$ & PDR & PNDR & PB \\
$L W$ & $D P R$ & $N D P R$ & $C P$ \\
\hline 300 & 791,70 & 95,40 & 887,10 \\
350 & 791,70 & 120,84 & 912,54 \\
400 & 791,70 & 147,84 & 939,54 \\
450 & 791,70 & 175,75 & 967,45 \\
500 & 791,70 & 204,2 & 995,90 \\
\hline
\end{tabular}

\section{Conclusões}

As exigências de proteína metabolizável para ganho de peso foram próximas às preconizadas pelo NRC (1996).

Sugere-se que, para conversão do ganho de peso vivo em ganho de peso vazio, deve-se multiplicar o ganho de peso vivo pelo fator 0,964 .

As exigências líquidas de energia para ganho de peso de zebuínos e seus mestiços, não-castrados, podem ser calculadas pela equação: $E R=0,044 *$ $\mathrm{PCVZ}^{0,75} * \mathrm{GDPCVZ}^{1,1578}$

\section{Referências Bibliográficas}

AGRICULTURAL AND FOOD RESEARCH COUNCIL AFRC. 1993. Energy and protein requeriments of ruminants. Wallingford: Commonwealth Agricultural Bureaux International. $159 \mathrm{p}$.

AGRICULTURAL RESEARCH COUNCIL - ARC. 1980. The nutrient requirements of ruminants livestock. London: Commonwealth Agricultural Bureaux. 351p.

BERG. R.T., BUTTERFIELD, R.M. 1976. New concepts of cattle growth. New York: Sydney University. 240p.

BYERS, F.M., ROMPALA, R.E. Level of energy effects on patterns and energetic efficiency of tissue deposition in small or large mature size beef cattle. In: MOUNT, L.E. (Ed.) SYMPOSIUM OF ENERGY METABOLISM, 8, Cambridge, 1980. Proceedings... Butterworths, London: EAAP Publ. n.28. 1980. p.141-146.

COELHO DA SILVA, J.F., LEÃO, M.I. Fundamentos de nutrição dos ruminantes. Piracicaba:Livroceres, 1979.380p.

FERREIRA, M.A. Desempenho, exigências nutricionais e eficiência de utilização da energia metabolizável para ganho de peso de bovinos 11 Simental x Nelore. Viçosa, MG:UFV, 1997.97 p. Tese (Doutorado em Zootecnia) - Universidade Federal de Viçosa, 1997.

FERREIRA, M.A., VALADARES FILHO, S.C., VALADARES, R.F.D. et al. Conteúdos corporais de proteína, gordura e energia de bovinos $\mathrm{F}_{1}$ Simental x Nelore, não-castrados. In: REUNIÃO ANUAL DA SOCIEDADE BRASILEIRA DE ZOOTECNIA, 35, 1998. Botucatu. Anais... Botucatu: SBZ, 1998a. p.260-262.
FERREIRA, M.A., VALADARES FILHO, S.C., VALADARES, R.F.D. et al. Exigências de proteína e energia para ganho de peso de bovinos $F_{1}$ Simental $x$ Nelore, nãocastrados. In: REUNIÃO ANUAL DA SOCIEDADE BRASILEIRA DEZOOTECNIA, 35, 1998. Botucatu.Anais... Botucatu: SBZ, 1998b. p.263-265

FERRELL, C.L., JENKINS, T.G. 1998a. Body composition and energy utilization by steers of diverse genotypes fed a highconcentrate diet during the finishing period: I. Angus, Belgian Blue, Hereford, and Piedmontese Sires. J. Anim. Sci., 76:637-646.

FERRELL, C.L., JENKINS, T.G. 1998b. Body composition and energy utilization by steers of diverse genotypes fed a highconcentrate diet during the finishing period: I. Angus, Belgian Blue, Hereford, and Piedmontese Sires. J. Anim. Sci., 76:647-657.

FONTES, C.A.A. Composição corporal, exigências líquidas de nutrientes para ganho de peso e desempenho produtivo de animais zebuínos e mestiços europeu-zebu. Resultados experimentais. In: SIMPÓSIO INTERNACIONAL SOBRE EXIGÊNCIAS NUTRICIONAIS DE RUMINANTES, 1995, Viçosa, MG. Anais... Viçosa, MG: DZO, 1995, p. 419-455.

GEAY, Y. 1984. Energy and protein utilization in growing cattle. J. Anim. Sci., 58(3):766-778.

GRANT, A.L., HELFERICH, W.G. 1991. An overview of growth. In: PEARSON, A. M. DUTSON, T.R. (Ed). Growth regulation in farm animals. London: Elsevier Applied Science. p.1-15.

HANKINS, O.G., HOWE, P.E. 1946. Estimation of the composition of beef carcasses and cuts. Washington, D.C. (Tech. Bulletin USDA, 926).

JONES, S.D.M., ROMPALA, R.E., JEREMIAH,L.E. 1985. Growth and composition of the empty body in steers of different maturity types fed concentrate or forage diets. J. Anim. Sci., 60(2):427-433.

NATIONAL RESEARCH COUNCIL - NRC. 1984. Nutrient requeriments of beef cattle. 6.ed. Washington, D.C. 90p.

NATIONAL RESEARCH COUNCIL - NRC. 1996. Nutrient requirements of beef cattle. 7.ed. Washington, D.C. 242p.

OWENS, F.N., GILL, D.R., SECRIST, D.S. et al. 1995. Review of some aspects of growth and devepopment of feedlot cattle. J. Anim. Sci., 73:3152-3172.

PAULINO, M.F., FONTES, C.A.A., JORGE, A.M. et al. Exigências de energia e proteína para ganho de peso de bovinos não castrados de quatro raças zebuínas em confinamento. In: REUNIÃO ANUAL DA SOCIEDADE BRASILEIRA DEZOOTECNIA, 34, Juiz de Fora, MG, 1997. Anais ... Juiz de Fora: SBZ, 1997, p. 16-18.

REGAZZI, J.A. 1996. Teste para verificar a identidade de modelos de regressão. Pesq. Agropec. Bras., 31(1):1-17.

ROBELIN, J., GEAY, Y. 1984. Body composition of cattle as affected by physiological status, breed, sex and diet. In: GILCHRIST, F.M.C., MACKIE, R.I (Eds.). Herbage nutrition in the subtropics and tropics. Johannesburg: Science Press. p.525-547.

SILVA, D.J. 1990. Análise de alimentos (métodos químicos e biológicos). Viçosa, MG: UFV. 165p.

VÉRAS, A.S.C., VALADARES FILHO, S.C.., COELHO DA SILVA, J.F. et al. 2000a. Consumo e digestibilidade aparente em bovinos Nelore, não-castrados, alimentados com rações contendo diferentes níveis de concentrado. Rev. bras. zootec., 29(6):2367-2378 (supl. 2).

VÉRAS, A.S.C., VALADARES FILHO, S.C., COELHO DA SILVA,J.F.et al. 2000b. Composição corporal e requisitos energéticos e protéicos de bovinos Nelore, não-castrados, alimentados com rações contendo diferentes níveis de concentrado. Rev. bras. zootec. 29(6):2379-2389 (supl. 2).

VÉRAS, A.S.C., VALADARES FILHO, S.C., COELHO DA SILVA, J.F. et al. 2001. Eficiência de utilização da energia metabolizável para mantença e ganho de peso e exigências de energia metabolizável e de nutrientes digestíveis totais de bovinos Nelore, não-castrados. Rev. bras. zootec., 30(3):904-910.

Recebido em: 14/12/99

Aceito em: 21/02/01 